\title{
Implementasi Customer Data Management Dalam Meningkatkan Retensi Pelanggan IndiHome di PT Telkom
}

\author{
Indah Pratiwi Fitriyani ${ }^{1}$, Chandra Hendriyani ${ }^{2}$ \\ ${ }^{1,2}$ Akademi Sekretari dan Manajemen Taruna Bakti \\ E-mail : ${ }^{1}$ indahpratiwi.mhs@asmtb.ac.id*,2chandra@asmtb.ac.id
}

\begin{abstract}
Abstrak
Agilitas pelanggan dan pesatnya perkembangan teknologi membuat perusahaan harus melakukan berbagai macam strategi salah satunya adalah meningkatkan retensi pelanggan agar pelanggan tidak beralih ke kompetitor. Oleh karena itu, perusahaan harus mengenal karakteristik pelanggannya secara spesifik diantaranya melalui pengolahan database pelanggan seperti Customer Data Management. Optimalisasi Customer Data Management dapat membuat perusahaan memahami kebutuhan dan keinginan dari pelanggan. PT Telkom sebagai salah satu Badan Usaha Milik Negara yang memiliki produk IndiHome yang merupakan market leader di Indonesia terus berusaha mempertahankan pangsa pasarnya agar pelanggannya tidak berpindah ke provider lain. Untuk menjaga retensi pelanggan PT Telkom merancang dan membuat strategi agar brand awereness IndiHome dapat terus meningkat dengan membuat program-program loyalitas pelanggan. IndiHome juga meningkatkan layanan dengan menambah variasi program atau channel TV Kabel, serta memberikan pelayanan yang cepat tanggap terhadap keluhan pelanggan sehingga citra perusahaan dan tingkat kepercayaan pelanggan semakin meningkat terlihat dari pangsa pasar dan kontunitas pelanggan menggunakan produk IndiHome. Customer Data Management berperan penting dalam perusahaan dengan kemampuan menganalisa data maka perusahaan dapat menciptakan kelangsungan bisnis di era digital saat ini dan data yang telah diperoleh dapat menjadi landasan keputusan dalam mengambil kebijakan bagi perusahaan.
\end{abstract}

Kata Kunci: Customer Data Management, Retensi pelanggan, IndiHome

\begin{abstract}
Customer agility and the rapid development of technology make companies have to carry out various strategies, one of which is increasing customer retention so that customers do not switch to competitors. Therefore, companies must know the characteristics of their customers specifically, including through customer database processing such as Customer Data Management. Optimization of Customer Data Management can make companies understand the needs and desires of customers. PT Telkom as one of the State-Owned Enterprises that has IndiHome products which is the market leader in Indonesia continues to try to maintain its market share so that its customers do not switch to other providers. To maintain customer retention, PT Telkom designed and developed a strategy so that the IndiHome brand awareness can continue to increase by creating customer loyalty programs. IndiHome also improves services by adding variations to Cable TV programs or channels, as well as providing services that are responsive to customer complaints so that the company's image and customer trust levels are increasing, as can be seen from the market share and customer continuity using IndiHome products. Customer Data Management plays an important role in companies with the ability to analyze data, so companies can create business continuity in the current digital era and the data that has been obtained can be the basis for decisions in making policies for the company.
\end{abstract}

Keywords: Customer Data Management, Customer Retention, IndiHome

1. PENDAHULUAN

Vol 7 No 2 - Agustus 2021 
Pesatnya perkembangan teknologi dan digitalisasi telah mendorong perusahaan untuk menjadikan teknologi sebagai platform bisnis untuk memenangkan persaingan. Transformasi teknologi telah merubah platform mereka menjadi digitalisasi bisnis dan melibatkan pelanggan meningkatkan daya saing dengan menciptakan kedekatan dan respon yang cepat [1]. Di era digital saat ini data dapat menjadi landasan bagi perusahaan dalam menyusun strategi bisnis dan membantu pimpinan dalam mengambil keputusan, membaca pasar keuangan [2], mengkontrol situasi [3], meminimalisir resiko [4]. Data memberi dampak semua sektor bisnis. Kemampuan dalam menganalisa data memberi peluang perusahaan untuk menguasai pangsa pasar salah satunya dengan menganalisis data pelanggan yang ada perusahaan akan mengetahui kebutuhan pelanggan secara terus menerus sehingga kelangsungan perusahaan dapat terus berlanjut.

Menurut Marchand \& Peppard (2013) terdapat 5 prinsip dalam mendukung keberhasilan mengelola data yaitu 1) Orang yang mengelola data 2)kemam puan menganalisa data menjadi nilai 3)melibatkan tenaga ahli 4) fokus pada pembelajaran 5)fokus pada pelanggan/bisnis. Pengelolaan data pelanggan sekarang menjadi suatu keharusan bagi perusahaan.

Sejak terjadinya pandemi Covid-19 di Indonesia bulan Maret tahun 2020 pemerintah menerapkan kebijakan kerja dari rumah atau Work From Home (WFH) dan belajar dari rumah. Penggunaan internet di Indonesia semakin meningkat dan berdasarkan data dari Kominfo(2021) jumlah pengguna internet di Indonesia meningkat menjadi 202,6 juta jiwa pada awal 2021 dari sebelumnya sebesar 196,7 juta jiwa. Jumlah ini meningkat 15,5\% atau 27 juta jiwa jika dibandingkan pada Januari 2020 seperti pada gambar 1.

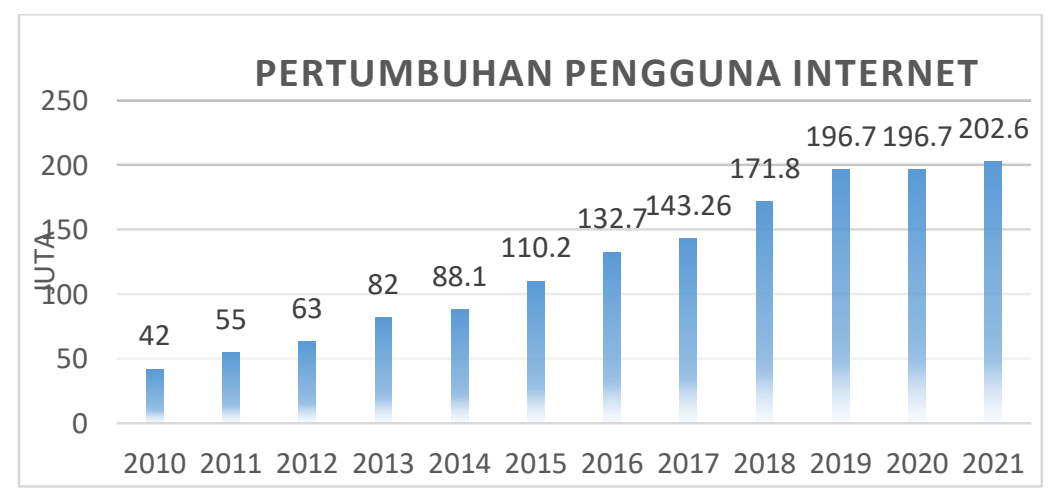

Gambar 1 : Grafik Pertumbuhan Pengguna Internet

Sumber : Kominfo (2010-2021)

Berdasarkan data pertumbuhan pengguna internet di atas yang semakin meningkat maka permintaan pelanggan terhadap akses intenet pun terus meningkat sesuai dengan kebutuhan. Dengan kondisi Work From Home (WFH) dan belajar dari rumah maka minat beli penguna internet pun tumbuh. Pertumbuhan pengguna internet yang semakin tinggi memunculkan tingkat persaingan antar bisnis provider di Indonesia. Di Indonesia sendiri terdapat beberapa perusahaan yang bergerak pada bidang telekomunikasi dimana pangsa pasar mencapai $86 \%$ dikuasai oleh Telkomsel, kedua Indosat, dan XL(CNBC,2020)

PT Telekomunikasi Indonesia (PT Telkom) yang merupakan perusahaan jasa telekomunikasi terbesar di Indonesia dan memiliki salah satu produk yaitu IndiHome sebagai bagian layanan informasi bagi masyarakat [5]. Indonesian Digital Home atau disingkat IndiHome adalah salah satu produk layanan dari PT. Telekomunikasi Indonesia berupa paket layanan internet ( internet on fiber atau high speed internet), layanan televisi interaktif (Use TV cable, IP $T V$ ) dan telepon rumah (voice). IndiHome memiliki kelebihan diantaranya jaringan internet yang super cepat dan stabil. PT Telkom sebagai market leader tetap harus menjaga loyalitas para pelanggannya agar tidak berpindah ke provider lainnya. Oleh karena itu, persaingan yang semakin pesat pada industri telekomunikasi di Indonesia menjadikan PT. Telkom harus dapat menjaga retensi pelanggan mereka [6].

Semakin meningkatnya kebutuhan internet maka permintaan masyarakat terhadap produk IndiHome semakin banyak dibutuhkan. Pengguna produk IndiHome Nasional pada tahun 2020 
sebanyak 8,3 juta pelanggan dibandingkan tahun 2019 hanya 7 juta pelanggan, kemudian pada tahun 2021 bertambah 1,6 juta pelanggan dan mencapai angka 9,7 juta pelanggan IndiHome tingkat Nasional. Pengguna IndiHome di Jawa Barat setiap tahunnya mengalami peningkatan dan pada tahun 2021 jumlah tersebut mencapai 873.000 pelanggan.

Menjaga retensi pelanggan merupakan cara yang tepat dalam suatu perusahaan untuk mempertahankan pelangganya agar tetap kembali menggunakan produk tersebut dalam waktu tertentu. Kaplan dan Norton (2000) mengatakan bahwa retensi pelanggan (customer retention) adalah suatu aktivitas yang diarahkan untuk mampu menjaga interaksi yang terus berkelanjutan dengan pelanggan melalui hubungan berkelanjutan, loyalitas pemasaran, database pemasaran, permission marketing, dan kemajuan-kemajuan [7]. Dalam mempertahankan pelanggan perusahaan harus mampu mengenal pelanggan lebih dalam agar perusahaan mengetahui kebutuhan dan keingginan pelanggan salah satu caranya dengan mengelola database pelanggan. Pada PT Telkom database ini dikelola oleh sistem Customer Data Management (CDM) .

Berdasarkan uraian di atas, penulis tertarik untuk meneliti lebih dalam mengenai Implementasi Customer Data Management (CDM) dalam mempertahankan retensi pelanggan IndiHome di PT Telkom Regional III Jawa Barat.

\section{METODE PENELITIAN}

Metode yang digunakan dalam penelitian ini adalah penelitian kualitatif dengan pendekatan deskriptif pada tinjauan literatur yang komprehensif serta data sekunder pelanggan IndiHome selama empat bulan di Jawa Barat yang mencapai 648.936 pelanggan high value customer yang terbagi menjadi kategori Silver, Gold, dan Platinum. Dalam penulisan jurnal ilmiah ini, metode yang digunakan dalam penelitian ini adalah penelitian kualitatif. Objek penelitian dilakukan di PT Telkom Regional III Jawa Barat yang merupakan perusahaan telekomunikasi terbesar di Indonesia.

\subsection{Tahapan Review}

\subsubsection{Customer Data Management (CDM )}

Customer Data Management mengeksplorasi data pelanggan dalam jumlah besar untuk menemukan pola dan kebiasaan pelanggan. Customer Data Management dimulai dengan pengumpulan data, kemudian melalui analisis menginformasikan atau menginspirasi tindakan dan menciptakan data yang menghasilkan lebih banyak lagi. Customer Data Management merupakan teknik yang menggabungkan teknik analisi data. Pengembangan data atau data mining dapat didefinisikan sebagai proses seleksi, eksplorasi dan pemodelan dari sejumlah besar data atau kecenderungan yang biasanya tidak disadari keberadaannya. Data disimpan secara elektronik dan di proses secara otomatis oleh komputer menggunakan teknik dan perhitungan tertentu. Data mining tersebut akan menjadi tolak ukur ataupun acuan untuk mengambil keputusan [8].

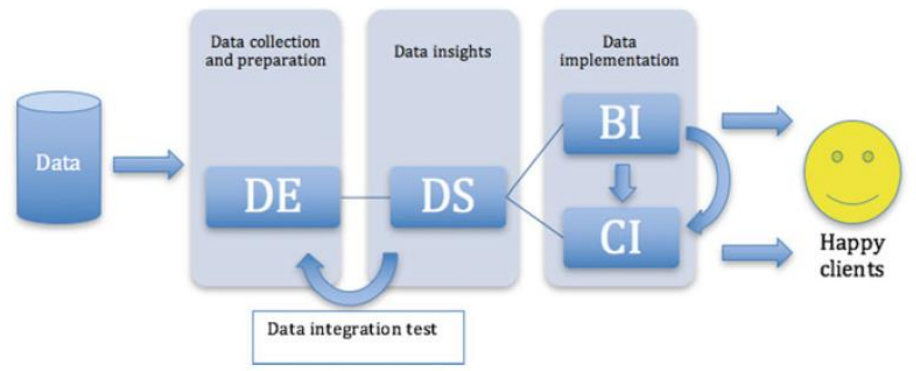

Gambar 2 : Alur Proses Data

Sumber : Corea (2019)

Dalam perusahaan alur proses data dimulai pada tahapan pengumpulan data dan persiapan data (data engineer), setelah pengumpulan data perusahaan mengolah data tersebut dan memelihara data tersebut untuk di identifikasi dan menghasilkan data yang tepat (data scientist). Data tersebut di komunikasikan dan digunakan oleh perusahaan untuk meningkatkan skalabilitas data yang dihasilkan (business intelligence). Alur proses data yang telah dihasilkan secara tepat oleh perusahaan dan kemudian dikomunikasikan dan diterapkan secara tepat dan baik dapat meningkatkan kepuasan pelanggan perusahaan (customer intelligence). 
Menyalurkan big data dapat menjadi strategi yang efektif untuk mengelola dan mengembangkan bisnis. Data dikumpulkan secara konsisten dari berbagai sumber dan terintegrasi oleh sistem, informasi yang dibuat dari data yang dikumpulkan akhirnya di validasi untuk menilai akurasi dan kelengkapan data tersebut [2].

Dalam mengimplementasikan sebuah strategi Customer Data Management diperlukan [9]:

1) Orang-orang yang profesional (kualifikasi yang memadai) bukan hanya mengerti tentang pelanggan tetapi juga mengerti menggunakan teknologi.

2) Proses di desain dengan baik dan teratur

3) Teknologi yang memadai (Leading-edge technology).

Database pelanggan merupakan salah satu aset utama perusahaan yang dapat dihitung performanya. Database pelanggan dapat menjadi ukuran tentang nilai perusahaan sekarang dan di masa mendatang. Adapun manfaat dari database pelanggan yaitu sebagai berikut [9] :

a) Dengan data profil yang lebih jelas, perusahaan akan lebih mudah untuk melihat kebutuhan yang berbeda-beda dari setiap pelanggan

b) Aktivitas komunikasi yang lebih targeted, perusahaan juga dapat memberikan penawaran produk ataupun layanan secara khusus untuk setiap pelanggan.

c) Dengan mengenali kebutuhan pelanggan dari data yang ada tentunya perusahaan lebih mudah untuk melakukan respon dan transaksi

d) Perusahaan dapat mendesain program loyalitas (loyalty program) yang sesuai untuk pelanggannya. Program loyalitas ini akan sangat membantu perusahaan di dalam mempertahankan pelanggan, meningkatkan kepuasan, dan menjaga agar pelanggan tidak tergiur oleh berbagai tawaran yang diberikan oleh pesaing lainnya.

\subsubsection{Retensi Pelanggan}

Retensi pelanggan adalah aktivitas penjualan perusahaan yang bertujuan untuk mengurangi hilangnya pelanggan. Retensi pelanggan yang sukses dimulai dengan kontak awal organisasi dengan pelanggan dan dilanjutkan dengan hubungan yang kontinu [10]. Retensi pelanggan dapat disorot sebagai niat pelanggan untuk melakukan pembelian berulang terhadap suatu produk.

Retensi pelanggan berarti sebuah upaya untuk tetap mengalokasikan sumber daya perusahaan agar kinerja perusahaan meningkat, dan akhirnya memberikan value yang lebih tinggi pada pelanggan sebagai dasar untuk mempertahankan pelanggan [7]. Retensi pelanggan ditentukan oleh "usaha perusahaan untuk dapat memuaskan berbagai kebutuhan pelanggan." Ukuran kepuasan pelanggan dapat memberikan feedback sebarapa baik perusahaan tersebut dalam membina bisnisnya. berikut[11]:

Menurut Kaplan dan Norton (2000), filosofi dari konsep customer value, sebagai

a) Perilaku pelanggan untuk saat ini dan masa lalu adalah alat prediksi yang tepat terhadap perilaku pelanggan untuk waktu yang akan datang.

b) Pelanggan yang aktif adalah pelanggan yang merasakan kebahagiaan ketika terjalin interaksi dengan perusahaan, mengendalikan pola perilaku, dan akhirnya berpengaruh terhadap pilihan, serta dapat merasakan sebuah kepuasan tersendiri. Maka dari itu perhatian terhadap pelanggan merupakan salah satu cara untuk dapat mengendalikan pelanggan dengan karakteristik yang dimiliki.

c) Retensi pemasaran adalah tentang aksi, reaksi, umpan balik dan pengulangan. Untuk itu, retensi dapat dilakukan jika telah sampai pada konsep aksi, dan terdapat umpan balik yang diterima atas aksi yang dilakukan oleh pemasar. Maka pengulangan terhadap program retensi pelanggan dapat memutuskan untuk dilanjutkan atau dihentikan.

d) Retensi pelanggan sebuah upaya untuk tetap mengalokasikan sumber daya perusahaan agar konerja perusahaan meningkat, dan akhirnya memberikan value yang lebih tinggi pada pelanggan sebagai dasar untuk mempertahankan pelanggan.

e) Retensi pelanggan juga dapat ditentukan oleh usaha perusahaan untuk dapat memuasakan kebutuhan pelanggan itu sendiri. Dari ukuran kepuasan pelanggan 
maka dapat memberikan feed back mengenai pelayanan ataupun seberapa baik perusahaan dalam menjalankan bisnis tersebut.

Kemampuan perusahaan untuk menarik dan mempertahankan pelanggan baru dengan cara layanan pelanggan yang ada, nilai pelanggan benar-benar menghasilkan sebagai hasil untuk menggunakan solusi, retensi pelanggan melibatkan lebih dari memberikan harapan, membangkitkan pendukung setia merek [12].

Manfaat dari mempertahankan pelanggan itu sendiri yaitu: 1) Biaya akuisisi pelanggan baru lebih berkurang 2) Penghematan biaya dimana seluruh biaya operasi untuk mencari pelanggan dapat ditekan dan berdampak positif pada profit perusahaan 3) Referalls, dimana pelanggan yang lama puas terhadap produk tersebut dan akan menyampaikan kepada calon pelanggan baru melalui word of mouth dan merekomendasikan perusahaan kepada calon pelanggan 4) Promosi premium, pelanggan merasa terpuaskan walaupun promosi sedikit lebih tinggi dikarenakan pelayanan yang diberikan sudah menyeluruh [7].

Dalam rangka mempertahankan pelanggan ada beberapa cara menurut DeSouza (Tjiptono dan Chandra: 2007) yaitu sebagai berikut:

a) Price, pelanggan harus diberikan promosi atau harga yang lebih murah dibanding dengan pesaing lainnya.

b) Product, pelanggan harus diberikan produk yang premium dari sebelumnya.

c) Service, pelayanan yang diberikan harus lebih baik dari sebelumnya.

d) Market, meningkatkan pasar kepada arah yang lebih luas.

e) Technological, teknologi yang tersedia harus lebih canggih dan dapat memudahkan konsumen dalam menggunakannya.

Retensi pelanggan dapat dilihat dengan membandingkan antara pelanggan yang keluar (churn) dan pelanggan yang tinggal (stay) semakin besar presentase pelanggan yang stay program retensi pelanggan pada perusahaan sudah baik. Berbagai macam program retensi yang dapat digunakan oleh perusahaan diantaranya adalah loyalty program, advertising and sales promotion [13]. Hal lain yang dapat berdampak bagi retensi pelanggan yaitu harga (price) [14].

Menurut Odekerken (2003) dan Gruen (1996) Pengukuran retensi pelanggan terbagi atas [15] :

1) Trust (Kepercayaan)

Kepercayaan merupakan keyakinan bahwa seseorang dapat menemukan apa yang mereka inginkan pada mitra pertukaran. Kepercayaan melibatkan kesediaan seseorang untuk bertingkah laku tertentu karema keyakinan bahwa mitranya akan memberikan apa yang di harapkan dan suatu harapan yang umumnya dimiliki seseorang bahwa kata, janji atau pernyataan orang lain dapat dipercaya (Barnes, 2003:148).

2) Satisfaction ( Kepuasan)

Faktor kepuasan pelanggan bukan jaminan mutlak bahwa pelanggan pasti kembali, tetapi menurut Philip Kotler, kunci dari keberhasilan retensi pelanggan adalah kepuasan pelanggan. Kepuasan pelanggan yang puas adalah yang menunjukan loyalitas pada periode waktu yang lama, yang mau merekomendasikan produk ataupun jasa ke teman atau relasinya, yang tidak mudah tertarik tawaran perusahaan lain.

3) Commitment (Komitmen)

Loyalitas dan retensi pelanggan dapat timbul bila ada kepercayaan terhadap merek produk atau jasa yang kuat. Rasa percaya ini makin lama akan membentuk komitmen yang kuat dan direfleksikan dengan sebuah komunikasi dan interaksi berkaitan dengan produk dari perusahaan. Komitmen yang tinggi akan mendorong pelanggan untuk membicarakan dan merekomendasikan kepada orang lain.

\section{HASIL DAN PEMBAHASAN}

IndiHome sebagai market leader dibidang layanan internet memiliki pertumbuhan dengan pendapatan senilai $\mathrm{Rp} 22,2$ triliun pada tahun 2020 atau tumbuh sebesar $21,2 \%$ dibandingkan pada pendapatan tahun 2019. PT Telkom dalam meningkatkan retensi pelanggan agar tetap bertahan menggunakan produk IndiHome maka PT Telkom membentuk Divisi Customer Care. Divisi Customer Care bertanggung jawab atas kualitas dan efektivitas 
penyelenggaraan layanan pelanggan, sehingga dapat dipastikan bahwa upaya pelayanan kepada pelanggan dilakukan secara kompetitif dan sesuai dengan karakteristik segmennya serta mampu secara efektif menjaga kepuasan pelanggan. Divisi ini yang memiliki kewenangan kepada Customer Data Management.

Proses Customer Data Management di IndiHome mulai dengan : a. Data Engineering berguna untuk mengolah data dengan jumlah yang besar dan data yang dikumpulkan diambil secara efisien pada PT Telkom pengolahan data dengan melakukan verifikasi data pelanggan dan menginput data-data tersebut ke dalam aplikasi $M y C x$ yang dimiliki oleh perusahaan Telkom. Data yang diverifikasi dapat dijadikan informasi bagi perusahaan untuk mengetahui jumlah pelanggan IndiHome setiap tahunnya, jumlah pelanggan yang mengajukan pemasangan maupun pelanggan yang mencabut dan mengvalidasi data reseller yang menyalahgunakan produk IndiHome dan diperjualbelikan secara illegal dimana semua informasi tersebut dapat dijadikan landasan dalam pengambilan keputusan oleh pimpinan; b. Data Scientist memproses dan mengolah data besar yang sudah dikumpulkan oleh data engineering dan pada tahap ini dilakukan pembuktian dengan memberikan saran dan keputusan yang tepat sesuai dengan perkembangan perusahaan PT Telkom melakukan proses untuk menggelompokan setiap data pelanggan berdasarkan layanan yang digunakan saat ini dan memiliki potensi untuk di upgrade paket layanan Indihome yang kecepatan mbps internetnya lebih besar dan pengelompokan data ini juga dapat digunakan untuk mengetahui komplain pelanggan salah satu contoh berdasarkan report data adanya reseller yang dapat merugikan pihak-pihak yang berlangganan yang dapat berakibat pada pemberhentian atau pencabutan produk IndiHome; c. Business Inteligence yaitu penggunaan data pelanggan untuk menyusun strategi dalam mengembangkan produk atau jangkauan dari layanan IndiHome. Selain itu Customer Data Management juga memberikan gambaran data alasan pelanggan mencabut produk IndiHome yaitu karena: 1) biaya pembayaran yang terlalu mahal 2) sering terjadinya gangguan 3) pindah alamat rumah dan membuat pelanggan jarang melakukan pemasangan ulang; d. Customer intelegence merupakan proses memetakan profile pelanggan. Profile pelanggan dibagi menjadi dua kategori yaitu reguler dan High Value Customer. Profil pelanggan memiliki peran yang utama terhadap perusahaan, karena kesuksesan perusahaan dipengaruhi oleh pelanggan. Semakin bertambahnya pelanggan maka loyalitas pelanggan terhadap perusahaan dapat terjaga dan pelanggan mampu menentukan keberhasilan dari perusahaan. Profil pelanggan membantu perusahaan untuk lebih mengenali pelanggan dengan baik serta dapat memberikan layanan yang sesuai dengan apa yang diinginkan dan dibutuhkan oleh pelanggan.

PT Telkom dalam mempertahankan pangsa pasar IndiHome melakukan beberapa strategi berdasarkan informasi yang diperoleh dari Customer Data Management yaitu dengan cara: a. Memberiikan keleluasaan kepada pelanggan untuk melakukan downgrade ataupun upgrade paket internet sesuai dengan kebutuhan dan kemampuan keuangan pelanggan salah satunya dengan mengubah menjadi paket internet saja; b. Cepat tanggap saat terjadinya gangguan karena saat terjadinya pandemi Covid-19 banyak masyarakat yang harus melakukan pekerjaan dari rumah yang membutuhkan internet dengan cepat maka perusahaan segera mengirimkan teknisi untuk segera memperbaiki gangguan tersebut. Keluhan pelanggan dapat dilaporkan kepada call center IndiHome di 147 yang aktif 24 jam; c. Produk IndiHome sendiri memiliki aplikasi My Indihome yang memudahkan pelanggannya untuk berkomunikasi sehingga pelanggan tidak perlu datang ke tempat langsung.

Salah satu manfaat dari Customer Data Management produk IndiHome yaitu dapat memetakan profile pelanggan. Dalam waktu 4 bulan (Januari -April 2021) pelanggan berdasarkan masa penggunaan internet dapat dikategorikan sebagai pelanggan reguler dan High Value Customer. Pelanggan IndiHome reguler merupakan customer yang baru memakai produk Indihome dan hanya memakai paket berupa paket layanan internet (internet on fiber atau high speed internet), layanan televisi interaktif (Use TV cable, IP TV) dan telepon rumah (voice), sedangkan High Value Customer merupakan reward bagi pelanggan setia IndiHome dengan minimal berlangganan 18 bulan mulai dari paket Rp300.000 - Rp700.000 atau berlangganan minimal 3 bulan untuk paket yang berlangganan di atas Rp700.000 serta pembayaran tagihan IndiHome setiap bulan lancar. High Value Customer dibagi menjadi tiga data kategori yaitu data pelanggan silver dengan kecepatan 20 mbps, kemudian gold dengan kecepatan 50 mbps, dan juga

Vol 7 No 2 - Agustus 2021 
platinum dengan kecepatan internet sampai 100 mbps. High Value Customer yang menjadi prioritas bagi IndiHome adapun data pelanggan 4 bulan terakhir adalah sebagai berikut:

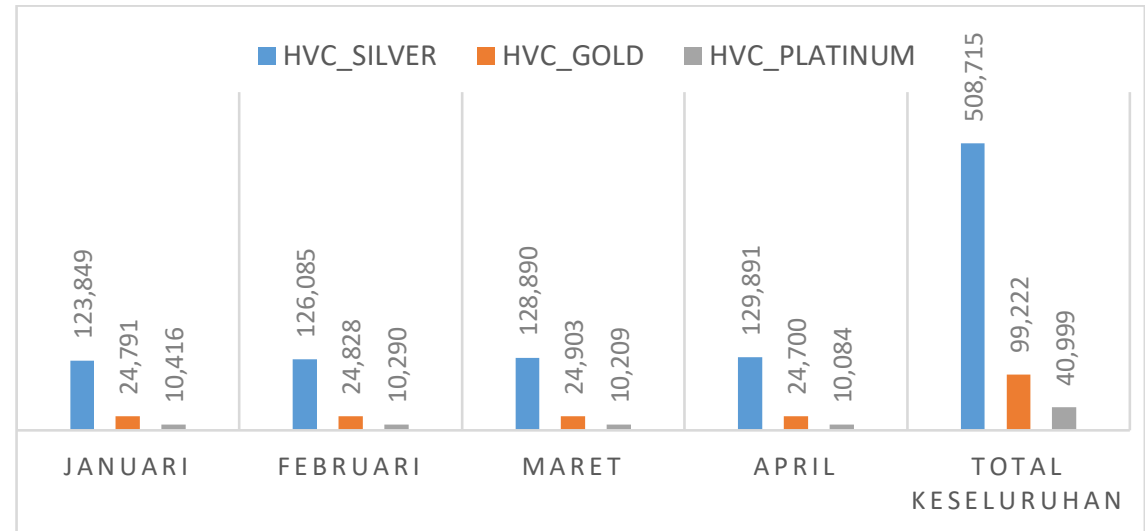

Gambar 3 : Grafik Jumlah High Value Customer dalam ribu Sumber: PT Telkom (Januari-April 2021)

Dari profile pelanggan reguler atau High Value Customer maka dapat mengetahui nilai harapan pelanggan terhadap produk IndiHome baik dari sisi kecepatan, biaya, dan program yang dibutuhkan oleh pelanggan. Adapun manfaat dari program High Value Customer yaitu sebagai berikut:1) Mendapatkan prioritas Praactive Maintenance untuk memastikan kualitas jaringan; 2) Mendapatkan antrian prioritas sehingga dapat dilayani lebih dahulu; 3) Mendapatkan special greeting ketika melakukan interaksi dengan Customer Touch Point; 4) Mendapat penanganan layanan yang lebih cepat dalam waktu penyelesaian gangguan; 5) Kesempatan untuk mendapatkan special reward lainnya dari IndiHome; 6) Mendapatkan lebih banyak poin MyIndiHome apabila melakukan pembayaran tagihan sebelum tanggal 10 setiap bulannya.

Adapun program loyalitas yang dilakukan untuk mempertahankan retensi pelanggan produk IndiHome PT Telkom melakukan beberapa cara seperti : 1) Program Loyalty Customer yaitu dengan

memberikan point kepada pelanggan yang telah setia menggunakan produk IndiHome. Point dapat dapat dikumpulkan dan ditukarkan dengan hadiah yang menarik seperti sepeda, tumbler, jam tangan, serta voucher belanja; 2) Untuk meningkatkan komunikasi dan kedekatan dengan pelanggan perusahaan sering mengadakan webinar mengenai produk ataupun kesehatan agar pelanggan tetap optimal di tengah pandemi salah satunya dengan tema webinar Good Life to Boost Your Mouth. Kegiatan ini diharapkan dapat turut meningkatkan brand awereness produk indihome; 3) Advertising merupakan upaya yang dilakukan PT Telkom untuk meningkatkan brand image dan pangsa pasar dari produk IndiHome Perusahaan menggunakan bebagai media advertising untuk menginformasikan produk-produk terbaru dari IndiHome dan untuk mengsosialisasikan program loyalty high value customer media yang digunakan diantaranya: instagram (indihome care), twitter (@indihome care), facebook (indihome care), dan youtube (telkom indonesia official). Business signal juga dioptimalkan oleh perusahaan untuk meningkatkan jalur komunikasi dengan pelanggan melalui whatsapp, dan juga voice message; 4 ) Sales Promotion merupakan salah satu metode yang digunakan oleh IndiHome dalam meningkatkan pangsa pasar dimana sales promotion ini dilakukan secara personal selling dan telle marketing oleh tim penjualan. Personal selling dilakukan secara door to door ke perumahan atau kantor, open table dilakukan di mall atau pameran, dan juga penyebaran brosur yang dilakukan oleh pegawai perusahaan yang bergerak di bidang marketing. Cara yang dilakukan perusahaan dalam mempromosikan produk secara personal merupakan cara yang efektif karena dapat berinteraksi langsung dengan pelanggan; 5) Customer Care merupakan unit yang dibentuk perusahaan khusus untuk mengelola layanan pada pelanggan, memelihar pelanggan, dan mempertahankan pelanggan. Customer care dibagi menjadi beberapa divisi seperti Customer Relationship Management, Customer Data Management, Customer Touch Point. Salah satu tugasnya adalah membuat program loyalitas pelanggan, memberikan pelayanan yang cepat 
tanggap, mengelola data pelanggan, mengirimkan notifikasi pembayaran melalui e-mail baik berupa tagihan maupun bukti pembayaran agar tidak terjadinya duplikat pembayaran dan mengirimkan undangan webinar melalui e-mail kepada pelanggan IndiHome; 6) Call Center menjadi salah satu bentuk pilihan IndiHome untuk meningkatkan retensi pelanggan. Layanan call center 24 jam diharapkan dapat menjawab keluhan keluhan pelanggan yang mungkin di alami pelanggan seperti gangguan, kecepatan layanan dalam menjanjikan perbaikan gangguan maksimal 3 jam setelah laporan diharapkan dapat meminimalisir terjadinya perpindahan pelanggan ke provider yang lain.

Dalam waktu empat bulan terakhir sempat terjadi penrunan pelanggan IndiHome sebesar 30\% dibulan Januari 2021, pada bulan Februari sebesar 12\%, pada bulan Maret sebesar $11 \%$, dan pada bulan April sebesar 9\% dari total pelanggan. Pada saat terjadi penurunan PT Telkom langsung melakukan program-program yang dapat meningkatkan kembali jumlah pelanggan yang menggunakan produk IndiHome. Untuk mengembalikan kepercayaan pelanggan IndiHome memberikan service yang baik bagi pelanggan, menanggapi keluhan secara professional, jika terjadi kerusakaan terhadap provider pelanggan tidak perlu mengeluarkan uang kembali dan dapat segera diganti oleh perusahaan. complain dari pelanggan perusahaan langsung cepat tanggap 1x24 jam, perusahaan memberikan program customer education dan customer experience sehingga pelanggan IndiHome menjadi pelanggan yang digital, IndiHome menjaga komitmen dengan meningkatkan kualitas dengan memanfaatkan Indonesia Digital Network yang berbasis teknologi fiber optic yang dapat digunakan dari ujung barat hingga ujung timur Indonesia. Pelanggan dapat memanfaatkan kecepatan internet yang tinggi dan kualitas koneksi yang stabil ataupun handal.

Adapun program loyalitas yang digunakan IndiHome untuk mempertahankan pelanggan diantaranya dengan pemberian open channel IndiHome, diskon upgrade system, dan pemberian flash point.

\section{Kesimpulan}

Berdasarkan hasil penelitian dan pembahasan maka dapat disimpulkan bahwa impelemntasi Customer Data Management pada produk Indihome yang dilakukan oleh PT Telkom selama ini dapat membantu PT Telkom dalam memetakan pelanggan Indihome secara optimal berdasarkan kebutuhan dan keinginan pelanggan, mengetahui tingkat kepuasan, loyalitas, dan harapan pelanggan terhadap produk Indihome. Database pelanggan digunakan sebagai landasan untuk mempertahankan kelangsungan bisnis perusahaan di era digital dan dapat meningkatkan upaya bisnis serta merancang strategi atau program yang harus dijalankan di kemudian hari. Retensi pelanggan yang tinggi bisa terjadi karena PT Telkom menggunakan Customer Data Management untuk mengenal perilaku pelangggannya secara detail sehingga dengan pemahaman tersebut PT Telkom dapat membuat program-program Indihome yang dapat membuat pelanggan bertahan dan tidak berpindah ke provider lain serta melakukan pembelian ulang terhadap produk atau jasa dari perusahaan,

\section{Saran}

Data base pelanggan merupakan hal yang penting bagi setiap perusahaan di era digital saat ini. Penggunaan data base dapat menjadi alat untuk memenangkan persaingan, persaingan saat ini karena dengan adanya data yang diperoleh maka memudahkan perusahaan untuk mendapatkan informasi yang dibutuhkan. Oleh karena itu penulis menyarankan perlu adanya penelitian lebih lanjut mengenai Customer Data Management dikaitkan dengan Customer Engagement dimana hasil penelitian ini bisa menjadi rujukan bagi para pelaku usaha. 


\section{DAFTAR PUSTAKA}

[1] C. Hendriyani and S. J. Raharja, "Analysis building customer engagement through e-CRM in the era of digital banking in Indonesia," Int. J. Econ. Policy Emerg. Econ., vol. 11, no. 5, pp. 479-486, 2018, doi: 10.1504/IJEPEE.2018.094820.

[2] F. Corea, An Introduction to Data. Everything You Need to Know About AI, Big Data and Data Science. 2019.

[3] M. Moeng and R. Melhem, "Applying statistical machine learning to multicore voltage \& frequency scaling," CF 2010 - Proc. 2010 Comput. Front. Conf., pp. 277-286, 2010, doi: $10.1145 / 1787275.1787336$.

[4] A. Veldhoen and S. De Prins, "Applying Big Data To Risk Management :," no. December, pp. 1-16, 2014.

[5] M. D. Maharani and T. Widodo, "Dampak Hubungan Karyawan Dengan Pelanggan Terhadap Loyalitas Pelanggan Indihome ( Studi Kasus Pada Pelanggan Indihome Di Kota Bandung ) The Impact Of Employee To Customer Relationship On Customers Loyalty In Indihome ( Case Study In Indihome Customers In ,”vol. 6, no. 2, pp. 2237-2244, 2019.

[6] M. H. Syahnur, M. Soeharijanto, and L. Tazlie, "Analisis Customer Experience Dengan Importance Performance Analysis (IPA) - Suatu Studi Pada Pelanggan Telkom Indihome Regional III Bandung," J. Manaj. Bisnis, vol. 5, no. 2, pp. 1-12, 2018, doi: 10.33096/jmb.v5i2.7.

[7] S. A. Sitorus, "Analisis Pengaruh Inovasi, Kualitas Jasa Dan Promosi Terhadap Retensi Pelanggan Pada Usaha Game Online Internet Di Kecamatan Medan Denai," J. Inform., vol. 1, no. 3, 2019, doi: 10.36987/informatika.v1i3.119.

[8] N. A. Hasibuan et al., "Implementasi Data Mining Untuk Pengaturan Layout," vol. 4, no. 4, pp. 6-11, 2017.

[9] C. Schawel and F. Billing, "Customer Relationship Management (CRM)," Top 100 Manag. Tools, vol. 2008, no. Snati, pp. 61-62, 2009, doi: 10.1007/978-3-8349-8185-1_19.

[10] O. Salim and S. Pujangkoro, "TERHADAP RETENSI PELANGGAN UNTUK PRODUK INDIHOME DI PT . TELKOM INDONESIA WITEL MEDAN,” vol. 6, no. 2, pp. 99$107,2016$.

[11] S. A. Sitorus, "Analisis Pengaruh Merk Dagang, Kualitas Jasa Dan Promosi Terhadap Retensi Pelanggan Pada Usaha Warung Selluler Di Kecamatan Medan Tembung," $J$. Inform., vol. 4, no. 2, pp. 14-25, 2019, doi: 10.36987/informatika.v4i2.231.

[12] N. D. Satriawan and N. Usman, "Effect of Commitment, Trust and Satisfaction of Customer Retention of Honda Motor Products Matic," J. Bus. Bank., vol. 8, no. 1, pp. 4557, 2018, doi: 10.14414/jbb.v8i1.1516.

[13] J. Kim, "The impact of different price promotions on customer retention," J. Retail. Consum. Serv., vol. 46, no. October, pp. 95-102, 2019, doi: 10.1016/j.jretconser.2017.10.007.

[14] Y. Polo, F. J. Sese, and P. C. Verhoef, "The Effect of Pricing and Advertising on Customer Retention in a Liberalizing Market," J. Interact. Mark., vol. 25, no. 4, pp. 201-214, 2011, doi: 10.1016/j.intmar.2011.02.002.

[15] R. Hurriyati and I. Widiastuti, "Pengaruh Pemasaran Eksperiensial Terhadap Retensi Pelanggan Pada Pengunjung Resort\&Spa Kampung Sampireun Garut,” Strateg. J. Pendidik. Manaj. Bisnis, vol. 8, no. 1, p. 1, 2008, doi: 10.17509/strategic.v8i1.995. 